\title{
Large-Dose Glucocorticoid Induced Secondary Adrenal Insufficiency in Spinal Cord Injury
}

\author{
Soo Ho Park, MD, Kang Hee Cho, MD, PhD
}

\begin{abstract}
Department of Rehabilitation Medicine, Chungnam National University School of Medicine, Daejeon, Korea
\end{abstract}
\begin{abstract}
Objective To investigate the incidence of adrenal insufficiency (AI) in patients with spinal cord injury (SCI) with symptoms similar to those of AI and to assess the relevance of AI and large-dose glucocorticoids in SCI.

Methods The medical records of 228 patients who were admitted to the rehabilitation center after SCI from January 2014 to January 2016 were reviewed retrospectively. Twenty-nine of 228 patients had persistent symptoms suspicious for AI despite continuous care for more than 4 weeks. Therefore, adrenocorticotropic hormone (ACTH) stimulation tests were conducted in these 29 patients.

Results Twelve of these 29 patients (41.4\%) with SCI who manifested AI-like symptoms were diagnosed as having AI. Among these 29 patients, 15 patients had a history of large- dose glucocorticoid treatment use and the other 14 patients did not have such a history. Ten of the 15 patients $(66.7 \%)$ with SCI treated with large-dose glucocorticoids after injury were diagnosed as having AI. In 12 patients with AI, the most frequent symptom was fatigue (66\%), followed by orthostatic dizziness (50\%), and anorexia (25\%). In the chi-square test, the presence of AI was positively correlated with large-dose glucocorticoid use ( $\mathrm{p}=0.008$, Fisher exact test).

Conclusion Among the patients with SCI who manifested similar symptoms as those of AI, high incidence of AI was found especially in those who were treated with large-dose glucocorticoids. During management of SCI, if a patient has similar symptoms as those of AI, clinicians should consider the possibility of AI, especially when the patient has a history of large-dose glucocorticoid use. Early recognition and treatment of the underlying AI should be performed.
\end{abstract}

Keywords Spinal cord injuries, Adrenal insufficiency, Glucocorticoids

\section{INTRODUCTION}

Adrenal insufficiency (AI) is a condition in which the adrenal glands do not produce adequate amounts of steroid hormones, primarily cortisol. AI impairs the body's ability to respond to stress during trauma and critical

Received April 5, 2016; Accepted June 14, 2016

Corresponding author: Soo Ho Park

Department of Rehabilitation Medicine, Regional Rehabilitation Center, Chungnam National University Hospital, Chungnam National University School of Medicine, 282 Munhwa-ro, Jung-gu, Daejeon 35015, Korea. Tel: +82-42-338-2460, Fax: +82-42-338-2461, E-mail: sso224@cnuh.co.kr ORCID: Soo Ho Park (http://orcid.org/0000-0002-1815-5196); Kang Hee Cho (http://orcid.org/0000-0002-6592-3370).

(c) This is an open-access article distributed under the terms of the Creative Commons Attribution Non-Commercial License (http://creativecommons.org/ licenses/by-nc/4.0) which permits unrestricted noncommercial use, distribution, and reproduction in any medium, provided the original work is properly cited. Copyright (c) 2016 by Korean Academy of Rehabilitation Medicine 
illness, worsening the overall clinical outcome [1]. Symptoms can include hypotension, decreased responsiveness to fluid and vasopressor therapy, hyperkalemia, and hyponatremia. Secondary AI is the consequence of dysfunction of the hypothalamic-pituitary component of the hypothalamic-pituitary-adrenal (HPA) axis, and it most commonly occurs from exogenous steroid use; the risk of developing $\mathrm{AI}$ is strongly related to the dose administered [2-4]. It is important to diagnose AI correctly because its presentation can be subtle, and failure of sufficient cortisol secretion during periods of acute stress may result in life-threatening adrenal crisis $[5,6]$.

Because it is difficult to recognize $\mathrm{AI}$ as the nonspecific nature of its symptoms is similar to that of spinal cord injury (SCI), AI in the presence of SCI presents unique challenges. For example, patients with SCI have an interruption of the efferent sympathetic activity that maintains blood pressure. This interruption combined with venous pooling, limited venous return and decreased cardiac output results in orthostatic hypotension [7]. The patients complain of weakness, weight loss and anorexia, which are also the symptoms of AI alone. Especially, in patients with SCI who have been treated with exogenous steroids, a higher level of suspicion is needed to recognize the underlying AI.

One study analyzed the incidence of AI in SCI patients, and there are a few case studies about AI in SCI patients after use of large-dose glucocorticoids. Pastrana et al. [8] reported that the incidence of AI in cervical SCI patients with neurogenic shock was $22 \%$ and the average basal cortisol was $9.3 \mu \mathrm{g} / \mathrm{dL}$ in patients with AI versus $29.2 \mu \mathrm{g} /$ $\mathrm{dL}$ in non-AI. However, to the best of our knowledge, a study assessing the incidence of AI in SCI patients with symptoms similar to those of AI is lacking.

Therefore, this study aimed to analyze the incidence of AI in SCI patients with symptoms similar to those of AI and to assess the relevance of AI and large-dose glucocorticoids in SCI. We also investigated the symptoms and signs which were manifested by SCI patients with AI.

\section{MATERIALS AND METHODS}

We retrospectively reviewed the medical records of patients with SCI older than 18 years who were admitted to the rehabilitation center from January 2014 to January 2016.
Through the medical records, we could note a history of steroid use in the emergency department. In patients transferred from other hospitals, we confirmed the history of steroid use through scanned medical records of the other hospitals or history taking.

We included patients who complained of at least one of the symptoms, signs and abnormalities of laboratory tests within 1 year from onset of SCI. Symptoms and signs in inclusion criteria were fatigue, weakness, orthostatic dizziness, weight loss, anorexia, refractory hypoglycemia (blood sugar levels below $70 \mathrm{mg} / \mathrm{dL}$ ) [9], low blood pressure (mean arterial pressure lower than $65 \mathrm{mmHg}$ ) [10], bradycardia (a heart rate of less than 50 beats/min) [11], postural hypotension (a fall in systolic blood pressure of at least $20 \mathrm{mmHg}$ or in diastolic blood pressure of at least $10 \mathrm{mmHg}$ when a person assumes a standing position) [12], and hyponatremia (serum Na level below $130 \mathrm{mEq} /$ L) [13] that had persisted and not improved despite continuous care for each symptom like proper nutritional support, medication adjustment, applying compressive stocking or abdominal binder and physical therapy for more than 4 weeks. The exclusion criteria were (1) a history of hypothalamic-pituitary diseases, (2) steroid or adrenal-suppressive drug use before SCI, (3) severe medical conditions like sepsis, pneumonia and acute respiratory distress syndrome during the hospital stay.

Patients who had symptoms of AI underwent the adrenocorticotropic hormone (ACTH) stimulation test, a safe and reliable tool with an excellent predictive diagnostic value. A vial of cosyntropin $250 \mu \mathrm{g}$ was given intravenously via a saline lock. Blood was drawn at baseline, 30 and 60 minutes after ACTH administration. Plasma cortisol levels were determined by radioimmunoassay. The cutoff value for AI was defined as cortisol levels of less than $18 \mu \mathrm{g} / \mathrm{dL}(500 \mathrm{nmol} / \mathrm{L})$ in the sampled plasma at 30 and 60 minutes after ACTH administration. Basal serum cortisol measurements were not used to diagnose AI, because baseline cortisol levels may be coincidentally low due to the physiologic diurnal rhythm of cortisol secretion. Peak cortisol level was defined as the highest level of cortisol after ACTH stimulation. Once AI is confirmed, measurement of plasma ACTH is the next step, with increased or inappropriately low levels defining primary and secondary origin of disease, respectively. 
Statistical analysis

All statistical analyses were performed using the SPSS software program ver. 19.0 (SPSS Inc., Chicago, IL, USA). Independent t-test for continuous variables and chi square test for categorical variables were used. To deal with the small number of subjects, we used Fisher exact test. Statistical significance was set at $\mathrm{p}<0.05$.

\section{RESULTS}

Two hundred twenty-eight patients were admitted with SCI during the study period. One hundred twenty of the

Table 1. Demographic and laboratory data for patients with SCI

\begin{tabular}{|c|c|c|c|c|c|c|c|c|}
\hline Sex/age & AIS & NLI & $\begin{array}{c}\text { Time after } \\
\text { onset } \\
\text { (day) }\end{array}$ & $\begin{array}{c}\text { Basal } \\
\text { cortisol level } \\
(\mu \mathrm{g} / \mathrm{dL})\end{array}$ & $\begin{array}{c}\text { Peak } \\
\text { cortisol level } \\
(\mu \mathrm{g} / \mathrm{dL})\end{array}$ & $\begin{array}{c}\text { ACTH } \\
\text { level } \\
\text { (pg/mL) }\end{array}$ & $\begin{array}{l}\text { Symptoms and signs } \\
\text { suspicious for AI }\end{array}$ & $\begin{array}{l}\text { Presence } \\
\text { of AI }\end{array}$ \\
\hline \multicolumn{9}{|c|}{ Non-steroid group ${ }^{\text {a) }}$} \\
\hline $\mathrm{M} / 78$ & A & $\mathrm{C} 3$ & 337 & 8.56 & 24.08 & 6.0 & Orthostatic dizziness, fatigue & $(-)$ \\
\hline $\mathrm{M} / 43$ & A & T3 & 61 & 18.03 & 22.92 & 98.6 & Orthostatic dizziness & $(-)$ \\
\hline $\mathrm{F} / 69$ & $\mathrm{D}$ & C5 & 89 & 9.24 & 14.69 & 59.1 & Fatigue, anorexia & $(+)$ \\
\hline $\mathrm{M} / 25$ & $\mathrm{C}$ & $\mathrm{C} 4$ & 185 & 9.08 & 22.75 & 1.1 & Anorexia, weakness & $(-)$ \\
\hline $\mathrm{M} / 39$ & $\mathrm{D}$ & C3 & 48 & 9.61 & 23.12 & 16.8 & Fatigue & $(-)$ \\
\hline $\mathrm{M} / 46$ & $\mathrm{D}$ & $\mathrm{C} 7$ & 316 & 9.85 & 17.11 & 57.5 & Fatigue & $(+)$ \\
\hline $\mathrm{M} / 62$ & B & $\mathrm{C} 8$ & 38 & 9.11 & 20.17 & 30.5 & Orthostatic dizziness & $(-)$ \\
\hline $\mathrm{F} / 81$ & $\mathrm{C}$ & $\mathrm{T} 10$ & 59 & 11.84 & 21.61 & 58.1 & Fatigue & $(-)$ \\
\hline $\mathrm{M} / 77$ & $\mathrm{D}$ & T5 & 39 & 12.07 & 21.24 & 26.4 & Fatigue, anorexia, weakness & $(-)$ \\
\hline $\mathrm{M} / 39$ & $\mathrm{D}$ & $\mathrm{C} 4$ & 100 & 13.03 & 24.10 & 66.4 & Fatigue, anorexia & $(-)$ \\
\hline $\mathrm{F} / 78$ & $\mathrm{C}$ & $\mathrm{C} 8$ & 40 & 9.54 & 22.34 & 3.3 & Fatigue, anorexia & $(-)$ \\
\hline $\mathrm{M} / 62$ & $\mathrm{C}$ & $\mathrm{C} 4$ & 48 & 20.43 & 30.79 & 16.9 & Orthostatic dizziness & $(-)$ \\
\hline $\mathrm{F} / 65$ & A & $\mathrm{C} 8$ & 28 & 3.21 & 19.46 & 11.7 & Fatigue & $(-)$ \\
\hline $\mathrm{M} / 25$ & A & $\mathrm{C} 3$ & 29 & 11.71 & 30.78 & 20.0 & Orthostatic dizziness & $(-)$ \\
\hline \multicolumn{9}{|c|}{ Steroid group ${ }^{\text {b) }}$} \\
\hline $\mathrm{F} / 67$ & $\mathrm{C}$ & $\mathrm{C} 4$ & 42 & 1.31 & 12.72 & 3.8 & Fatigue, orthostatic dizziness & $(+)$ \\
\hline $\mathrm{M} / 48$ & $\mathrm{D}$ & $\mathrm{C} 4$ & 39 & 0.47 & 4.82 & 2.5 & Fatigue, anorexia & $(+)$ \\
\hline $\mathrm{M} / 54$ & $\mathrm{D}$ & $\mathrm{C} 4$ & 132 & 10.41 & 30.14 & 5.9 & Fatigue & $(-)$ \\
\hline $\mathrm{M} / 73$ & $\mathrm{D}$ & $\mathrm{C} 4$ & 28 & 1.94 & 12.61 & 1.9 & Orthostatic dizziness & $(+)$ \\
\hline $\mathrm{M} / 38$ & A & $\mathrm{T} 10$ & 42 & 2.08 & 13.98 & 9.0 & Fatigue, orthostatic dizziness & $(+)$ \\
\hline $\mathrm{M} / 74$ & $\mathrm{D}$ & $\mathrm{C} 3$ & 31 & 1.36 & 12.06 & 2.2 & Fatigue & $(+)$ \\
\hline $\mathrm{M} / 20$ & B & C5 & 34 & 13.33 & 24.83 & 56.3 & Fatigue, weakness & $(-)$ \\
\hline $\mathrm{M} / 24$ & $\mathrm{C}$ & $\mathrm{C} 4$ & 34 & 12.54 & 31.21 & 78.4 & Orthostatic dizziness & $(-)$ \\
\hline $\mathrm{M} / 48$ & $\mathrm{D}$ & C3 & 29 & 0.69 & 6.21 & 1.2 & Orthostatic dizziness & $(+)$ \\
\hline $\mathrm{M} / 62$ & $\mathrm{C}$ & $\mathrm{T} 12$ & 39 & 12.41 & 31.99 & 50.7 & Fatigue, weakness & $(-)$ \\
\hline $\mathrm{M} / 63$ & $\mathrm{C}$ & C5 & 45 & 0.27 & 3.17 & 3.8 & Fatigue, orthostatic dizziness & $(+)$ \\
\hline $\mathrm{M} / 49$ & $\mathrm{D}$ & C5 & 39 & 8.45 & 15.09 & 8.2 & Fatigue, anorexia & $(+)$ \\
\hline $\mathrm{M} / 61$ & A & C5 & 263 & 14.25 & 17.78 & 9.6 & Orthostatic dizziness & $(+)$ \\
\hline $\mathrm{M} / 57$ & $\mathrm{D}$ & C5 & 108 & 2.25 & 13.25 & 7.1 & Fatigue, weakness & $(+)$ \\
\hline $\mathrm{M} / 36$ & $\mathrm{C}$ & $\mathrm{T} 6$ & 217 & 17.82 & 34.27 & 37.4 & Fatigue, orthostatic dizziness & $(-)$ \\
\hline
\end{tabular}

SCI, spinal cord injury; AIS, American Spinal Injury Association (ASIA) impairment scale; NLI, neurological level of injury; ACTH, adrenocorticotropic hormone; AI, adrenal insufficiency.

${ }^{\text {a) }}$ Patients not treated with the 24- to 48-hour glucocorticoid regimen after injury, ${ }^{\text {b) }}$ patients treated with the 24 - to 48 hour glucocorticoid regimen after injury. 
228 patients were categorized to the group treated with large-dose glucocorticoids after injury and the remaining 108 patients were categorized to the group not treated with large-dose glucocorticoids. Fifteen and fourteen patients in each group had symptoms suspicious for AI despite continuous care for more than 4 weeks. Therefore, ACTH stimulation tests were conducted in these 29 patients. Twelve of these 29 patients $(41.4 \%)$ who had similar symptoms as those of AI met the criteria for AI on the ACTH stimulation test. In 12 patients with AI, the most frequent symptom was fatigue $(66 \%)$, followed by orthostatic dizziness (50\%), and anorexia (25\%) (Table 1).

Fifteen of the 29 symptomatic patients had a history of treatment with large-dose glucocorticoids after spinal cord injury (Fig. 1). The average basal cortisol was 6.77 $\mu \mathrm{g} / \mathrm{dL}$ in the 15 symptomatic patients treated with largedose glucocorticoids versus $11.25 \mu \mathrm{g} / \mathrm{dL}$ in the 14 patients not treated with large-dose glucocorticoids. The average peak cortisol after ACTH stimulation test was $17.60 \mu \mathrm{g} / \mathrm{dL}$ in patients treated with large-dose glucocorticoids versus $20.80 \mu \mathrm{g} / \mathrm{dL}$ in patients not treated with large-dose glucocorticoids (Table 2).

Among the 12 patients with AI, 10 patients treated with large-dose glucocorticoids showed low ACTH levels below the lower limit of the normal range (range, 10-60 pg/ $\mathrm{mL}$ ). The other 2 patients also showed a positive response to ACTH stimulation test although they were not treated with steroid therapy after SCI. However, these 2 patients showed a relatively higher ACTH level $(57.5 \mathrm{pg} / \mathrm{mL}, 59.1$ $\mathrm{pg} / \mathrm{mL}$ ) (Table 1).

Among the 29 patients, the number of patients diagnosed with AI is shown in Table 3. In chi-square test, we found a significantly high prevalence of $\mathrm{AI}$ in the group treated with large-dose glucocorticoids (10 of the 15 patients, $66.7 \%$ ) compared with the group not treated with large-dose glucocorticoids ( 2 of the 14 patients, $14.3 \%$ ) $(\mathrm{p}=0.008$, Fisher exact test).

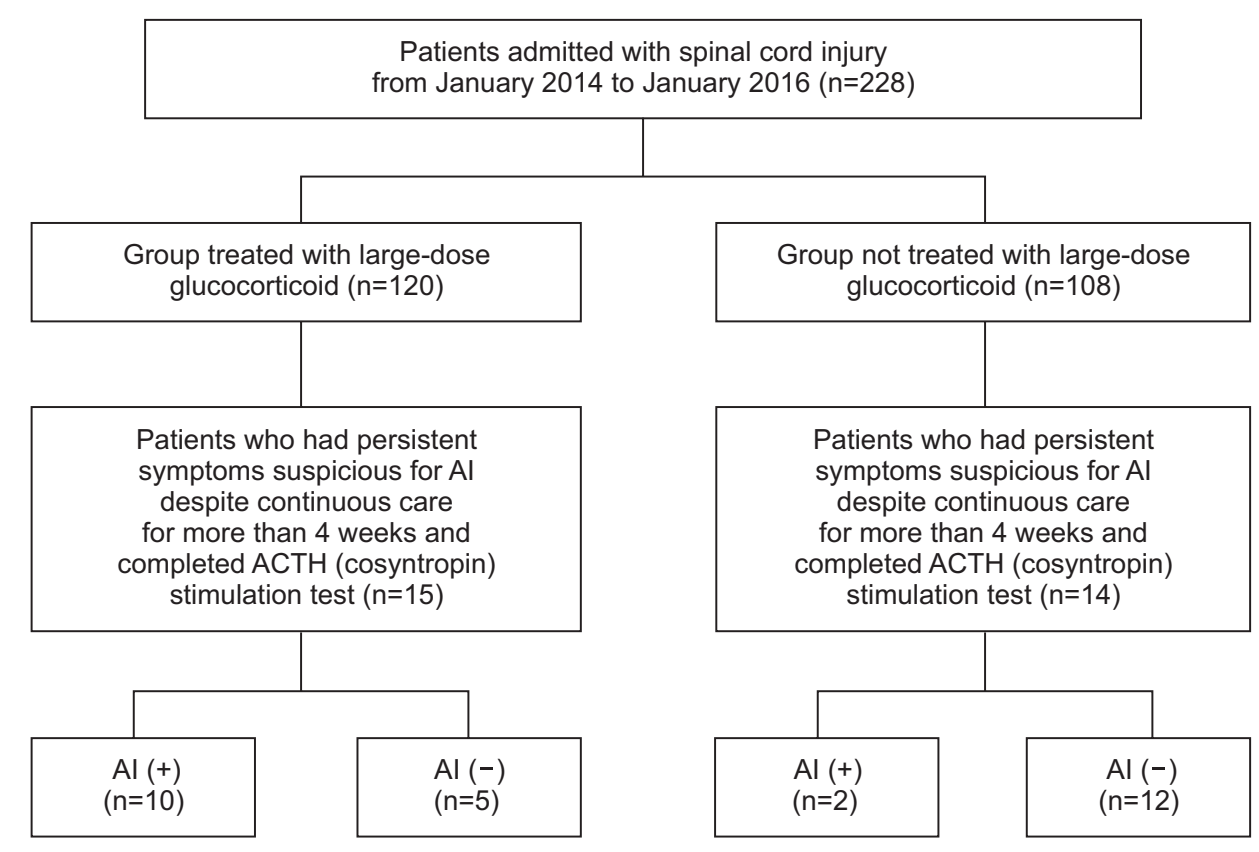

Fig. 1. Patient flow chart. ACTH, adrenocorticotropic hormone; AI, adrenal insufficiency.

Table 2. Comparison of the mean basal and peak cortisol levels

\begin{tabular}{lccc}
\hline & $\begin{array}{c}\text { Patients treated with large-dose } \\
\text { glucocorticoids }(\mathbf{n = 1 5})\end{array}$ & $\begin{array}{c}\text { Patients not treated with large-dose } \\
\text { glucocorticoids }(\mathbf{n = 1 4})\end{array}$ & $\begin{array}{c}\text { p-value } \\
\text { Basal cortisol }(\mu \mathrm{g} / \mathrm{dL})\end{array}$ \\
Peak cortisol $^{\mathrm{a})}(\mu \mathrm{g} / \mathrm{dL})$ & $6.77 \pm 6.16$ & $11.25 \pm 4.15$ & $0.029^{*}$ \\
\hline
\end{tabular}

Values are presented as mean \pm standard deviation.

${ }^{a}$ Highest level of cortisol after adrenocorticotropic hormone stimulation.

${ }^{*} \mathrm{p}<0.05$. 
Large-Dose Glucocorticoid Induced Secondary Adrenal Insufficiency in Spinal Cord Injury

Table 3. Number of patients diagnosed with adrenal insufficiency

\begin{tabular}{lccc}
\hline & $\begin{array}{c}\text { Patients treated with large-dose } \\
\text { glucocorticoids }(\mathbf{n}=15)\end{array}$ & $\begin{array}{c}\text { Patients not treated with large-dose } \\
\text { glucocorticoids }(\mathbf{n}=14)\end{array}$ & p-value $^{\text {a) }}$ \\
\hline Adrenal insufficiency & $10(66.7)$ & $2(14.3)$ & 0.008 \\
\hline
\end{tabular}

Values are presented as number (\%).

${ }^{a)}$ Fisher exact test.

\section{DISCUSSION}

Although high-dose glucocorticoid administration after acute SCI is not currently recommended as the standard of care, 24- to 48-hour glucocorticoid regimen is still a treatment option after acute SCI $[14,15]$. The prolonged use of glucocorticoids causes complications such as AI. However, a study assessing the incidence of AI in SCI patients treated with large-dose glucocorticoids suggested by the National Acute Spinal Cord Injury Study (NASCIS) trials is lacking. Accordingly, this study aimed to analyze the incidence of $\mathrm{AI}$ in patients with SCI with symptoms similar to those of $\mathrm{AI}$ and to assess the relevance of $\mathrm{AI}$ and large-dose glucocorticoids in SCI. To the best of our knowledge, the current research is the first study to identify the incidence of AI in symptomatic SCI patients treated with large-dose glucocorticoids.

The findings of our study suggest that a significant number of patients with SCI who manifested similar symptoms as those of AI were diagnosed as having AI (41.4\%) and the prevalence of AI was higher in patients treated with large-dose glucocorticoids after SCI (66.7\%). Pastrana et al. [8] reported that the incidence of AI in cervical SCI patients with neurogenic shock was $22 \%$, which is much lower than that in our study. One explanation for this result is the difference in diagnostic criteria for AI. In our study, the cutoff for failure was defined as cortisol levels of less than $18 \mu \mathrm{g} / \mathrm{dL}$ sampled at 30 and 60 minutes after ACTH stimulation. However, in the study conducted by Pastrana et al. [8], AI was defined as basal cortisol levels less than $15 \mu \mathrm{g} / \mathrm{dL}$ in the presence of neurogenic shock. Another explanation is that steroids for treatment of SCI were not administered as part of the spinal cord protection protocol in that study because of the long-term complications. Therefore, these differences in diagnostic criteria and subjects might have affected the incidence of AI.

AI can easily be overlooked in SCI as similar nonspecific symptoms occur frequently after SCI. Most of the symptoms of cortisol deficiency such as fatigue, weakness, orthostatic dizziness, weight loss and anorexia are nonspecific [16] and usually occur similarly after SCI. AI should be suspected based on the presenting symptoms. In our patients with $\mathrm{AI}$, the most frequent symptom was fatigue, followed by orthostatic dizziness and anorexia. Identifying the presence of AI in patients with SCI is important because its symptoms such as hypotension, weakness and lethargy can easily be mistaken for other diseases. Unless many patients with SCI who have AI are diagnosed, there is a possibility that they might be treated inappropriately. In our hospital, patients with symptomatic AI were treated with hydrocortisone in the early morning and afternoon. The usual initial dose was $25 \mathrm{mg}$ of hydrocortisone (divided into doses of 15 and 10 $\mathrm{mg}$ ) or $37.5 \mathrm{mg}$ of cortisone (divided into doses of 25 and $12.5 \mathrm{mg}$ ), but the daily dose was decreased to 20 or 15 mg of hydrocortisone. The goal was to use the smallest dose that relieves the patient's symptoms of AI in order to prevent weight gain and osteoporosis. After use of hydrocortisone, the patient's well-being, symptoms of AI and physical strength were improved.

In our study, 10 patients who were treated with largedose glucocorticoids after SCI and were diagnosed with AI showed low ACTH levels below the lower limit of the normal range. Based on this fact, we could determine that suppression of the HPA axis had occurred in these patients. On the other hand, 2 patients were diagnosed with AI although they were not treated with steroid therapy after SCI. In comparison with 10 patients with a history of large- dose glucocorticoid use, 2 patients showed a relatively higher ACTH level. This suggests that the cause of AI might not be secondary origin like exogenous steroids in these 2 patients who were not treated with steroid therapy.

Lipiner-Friedman et al. [17] reported that impairment in adrenal reserves had been documented in chronic SCI patients. It is also well documented that neuroendocrine changes can occur after SCI, although most of these hor- 
monal secretions are regulated by feedback systems external to the spinal cord [18]. However, there is little evidence that SCI by itself can cause AI [19]. It is well known that administration of exogenous steroids in SCI has the potential to suppress the HPA function. Case reports demonstrated that only 24 hours of high-dose steroids predisposes persons to secondary AI [1]. Therefore, these studies support our findings that glucocorticoids administered may be temporally associated with the development of AI, after other causes like primary adrenal diseases and adrenal-suppressive drug use were eliminated.

Although the definitive cause of AI in SCI patients remains unclear, we found that the use of glucocorticoids may be associated with the development of AI. In spite of clinical glucocorticoid use in patients with acute SCI, empirical evidence on the management of SCI is lacking. The use of methylprednisolone administration in the treatment of acute SCI is not proven as a standard of care, nor can it be considered a recommended treatment. Evidence of the drug's efficacy and impact is weak and may only represent random events $[14,15]$. Despite these facts from research, 24- to 48-hour glucocorticoid regimens suggested by the NASCIS trials II and III [20-23] are treatment options and frequent components of SCI management [24]. Regarding the high incidence of AI and suspicious effects of steroids, a high level of suspicion is needed to recognize the underlying AI in patients with SCI who have been treated with large-dose glucocorticoids.

Our report also has some limitations. First, the sample size was relatively small. In addition, we included only those patients with SCI who had persistent symptoms suspicious for AI and they were not representative of the general population of SCI because we could not perform the cosyntropin test in asymptomatic patients. Second, data on steroid dose and treatment duration was not collected; thus, we were unable to correlate steroid dose and duration with the incidence of AI. Further studies to verify the incidence of $\mathrm{AI}$ and its complications in larger cohorts along with studies on the underlying pathophysiology are needed.

In conclusion, among patients with SCI who manifested similar symptoms as those of AI, high incidence of AI was found especially in patients treated with largedose glucocorticoids. To the best of the authors' knowledge, this is the first study to investigate the incidence of AI in patients treated with large-dose glucocorticoids after SCI. During management of SCI, if a patient has refractory symptoms like fatigue, orthostatic dizziness and anorexia, clinicians should consider the possibility of AI, especially when a patient has a history of largedose glucocorticoid use. Early recognition and treatment of the underlying AI should be performed to prevent lifethreatening conditions.

\section{CONFLICT OF INTEREST}

No potential conflict of interest relevant to this article was reported.

\section{REFERENCES}

1. Garcia-Zozaya IA. Adrenal insufficiency in acute spinal cord injury. J Spinal Cord Med 2006;29:67-9.

2. Bracken MB, Collins WF, Freeman DF, Shepard MJ, Wagner FW, Silten RM, et al. Efficacy of methylprednisolone in acute spinal cord injury. JAMA 1984;251:45-52.

3. Hawryluk GW, Rowland J, Kwon BK, Fehlings MG. Protection and repair of the injured spinal cord: a review of completed, ongoing, and planned clinical trials for acute spinal cord injury. Neurosurg Focus 2008;25:E14.

4. Mortimer KJ, Tata LJ, Smith CJ, West J, Harrison TW, Tattersfield AE, et al. Oral and inhaled corticosteroids and adrenal insufficiency: a case-control study. Tho$\operatorname{rax} 2006 ; 61: 405-8$.

5. Shulman DI, Palmert MR, Kemp SF; Lawson Wilkins Drug and Therapeutics Committee. Adrenal insufficiency: still a cause of morbidity and death in childhood. Pediatrics 2007;119:e484-94.

6. Crowley RK, Argese N, Tomlinson JW, Stewart PM. Central hypoadrenalism. J Clin Endocrinol Metab 2014;99:4027-36.

7. Bornstein SR, Engeland WC, Ehrhart-Bornstein M, Herman JP. Dissociation of ACTH and glucocorticoids. Trends Endocrinol Metab 2008;19:175-80.

8. Pastrana EA, Saavedra FM, Murray G, Estronza S, Rolston JD, Rodriguez-Vega G. Acute adrenal insufficiency in cervical spinal cord injury. World Neurosurg 2012;77:561-3.

9. Cryer PE, Axelrod L, Grossman AB, Heller SR, Montori 
VM, Seaquist ER, et al. Evaluation and management of adult hypoglycemic disorders: an Endocrine Society Clinical Practice Guideline. J Clin Endocrinol Metab 2009;94:709-28.

10. Sesso HD, Stampfer MJ, Rosner B, Hennekens CH, Gaziano JM, Manson JE, et al. Systolic and diastolic blood pressure, pulse pressure, and mean arterial pressure as predictors of cardiovascular disease risk in men. Hypertension 2000;36:801-7.

11. Field JM, Hazinski MF, Sayre MR, Chameides L, Schexnayder SM, Hemphill R, et al. 2010 American Heart Association guidelines for cardiopulmonary resuscitation and emergency cardiovascular care science. Circulation 2010;122(Suppl 3):S639-S946.

12. Logan IC, Witham MD. Efficacy of treatments for orthostatic hypotension: a systematic review. Age Ageing 2012;41:587-94.

13. Reynolds RM, Padfield PL, Seckl JR. Disorders of sodium balance. BMJ 2006;332:702-5.

14. Hurlbert RJ. Methylprednisolone for acute spinal cord injury: an inappropriate standard of care. J Neurosurg 2000;93(1 Suppl):1-7.

15. Bydon M, Lin J, Macki M, Gokaslan ZL, Bydon A. The current role of steroids in acute spinal cord injury. World Neurosurg 2014;82:848-54.

16. Oelkers W. Adrenal insufficiency. N Engl J Med 1996;335:1206-12.

17. Lipiner-Friedman D, Sprung CL, Laterre PF, Weiss Y, Goodman SV, Vogeser M, et al. Adrenal function in sepsis: the retrospective CORTICUS cohort study. Crit Care Med 2007;35:1012-8.

18. Huang TS, Wang YH, Lee SH, Lai JS. Impaired hypothalamus-pituitary-adrenal axis in men with spinal cord injuries. Am J Phys Med Rehabil 1998;77:108-12.
19. Zeitzer JM, Ayas NT, Shea SA, Brown R, Czeisler CA. Absence of detectable melatonin and preservation of cortisol and thyrotropin rhythms in tetraplegia. J Clin Endocrinol Metab 2000;85:2189-96.

20. Bracken MB, Shepard MJ, Collins WF, Holford TR, Young W, Baskin DS, et al. A randomized, controlled trial of methylprednisolone or naloxone in the treatment of acute spinal-cord injury. Results of the second National Acute Spinal Cord Injury Study. N Engl J Med 1990;322:1405-11.

21. Bracken MB, Shepard MJ, Collins WF Jr, Holford TR, Baskin DS, Eisenberg HM, et al. Methylprednisolone or naloxone treatment after acute spinal cord injury: 1-year follow-up data. Results of the second National Acute Spinal Cord Injury Study. J Neurosurg 1992;76:23-31.

22. Bracken MB, Shepard MJ, Holford TR, Leo-Summers L, Aldrich EF, Fazl M, et al. Administration of methylprednisolone for 24 or 48 hours or tirilazad mesylate for 48 hours in the treatment of acute spinal cord injury. Results of the third National Acute Spinal Cord Injury randomized controlled trial. National Acute Spinal Cord Injury Study. JAMA 1997;277:1597-604.

23. Bracken MB, Shepard MJ, Holford TR, Leo-Summers L, Aldrich EF, Fazl M, et al. Methylprednisolone or tirilazad mesylate administration after acute spinal cord injury: 1-year follow up. Results of the third National Acute Spinal Cord Injury randomized controlled trial. J Neurosurg 1998;89:699-706.

24. Omori N, Takada E, Narai H, Tanaka T, Abe K, Manabe Y. Spontaneous cervical epidural hematoma treated by the combination of surgical evacuation and steroid pulse therapy. Intern Med 2008;47:437-40. 